\title{
PERILAKU YANG BERHUBUNGAN DENGAN PEDICULOSIS CAPITIS PADA SISWI MADRASAH TSANAWIYAH HIFZIL QUR'AN MEDAN
}

\author{
Salbiah \\ Poltekkes Kemenkes Medan \\ email: salbiah.khamaruddin80@gmail.com
}

\begin{abstract}
Pediculosis Capitis is an infestation Pediculus humanus var. capitis or commonly known as head lice on human hair and scalp. The disease had become endemic around the world, both in developed and developing countries, with most of infestation occurring in school-age children. The study aims to know the relationship between behavior with incidence of Pediculosis Capitis on Madrasah Tsanwiyah Hifzil Qur'an Medan students. Type of study used is analytic study with cross sectional design. Samples amounted to 71 respondents. Sample were drawn by simple random sampling method. Data obtained by way of filling questionnaire and hair examination directly. Data then analyzed with chi-square test. The result showed that from 71 respondents, 57 respondents (80,3\%) had Pediculosis Capitis. The result also showed that there are no relationship between knowledge and attitude with incidence of Pediculosis Capitis ( $p$-value $=0,757$ and 0,309). There are relationship between action with incidence of Pediculosis Capitis with p-value $=0,005$. The high prevalence of Pediculosis Capitis in these Madrasah Tsanwiyah Hifzil Qur'an Medan students needs to get more serious treatment. Recomended for students to pay more attention to the things that can help spread the Pediculosis Capitis.
\end{abstract}

Keywords: Pediculosis Capitis, Knowledge, Attitude, Practice

\begin{abstract}
ABSTRAK
Pediculosis Capitis adalah infestasi Pediculus humanus var. capitis atau yang biasa disebut kutu kepala pada rambut dan kulit kepala manusia. Penyakit ini telah menjadi endemik di seluruh dunia baik di negara maju maupun di negara berkembang, dengan sebagian besar infestasi terjadi pada anak-anak usia sekolah. Penelitian ini bertujuan untuk mengetahui hubungan antara perilaku dengan kejadian Pediculosis Capitis pada siswi Madrasah Tsanwiyah Hifzil Qur'an Medan. Penelitian ini merupakan penelitian survey deskriptif dengan desain cross sectional dengan sampel berjumlah 71 responden. Analisa data menggunakan uji chi-square. Hasil penelitian menunjukkan sebagian besar siswi (80,3\%) menderita Pediculosis Capitis. Tingkat pengetahuan responden dalam kategori baik yaitu sebanyak 74,6\%. Sikap siswa juga sebagian besar dalam kategori baik 52,1\%, namun tindakan siswa sebagian besar dalam kategori tidak baik 56,9\%. Hasil penelitian menunjukkan tidak ada hubungan yang bermakna antara pengetahuan dan sikap dengan kejadian Pediculosis Capitis ( $p$-value $=0,757$ dan 0,309) serta ada hubungan yang bermakna antara tindakan dengan kejadian Pediculosis Capitis dengan ( $p$-value $=0,005$ ). Tingginya prevalensi Pediculosis Capitis pada siswi Madrasah Tsanawiyah Hifzil Qur'an Medan ini perlu mendapatkan penanganan yang lebih serius. Disarankan bagi para siswi agar lebih memperhatikan hal-hal yang dapat membantu penyebaran Pediculosis Capitis.
\end{abstract}

Kata kunci : Pediculosis Capitis, Pengetahuan, Sikap, Tindakan 


\section{PENDAHULUAN}

Perilaku adalah semua kegiatan atau aktivitas manusia yang merupakan suatu respons atau reaksi seseorang terhadap stimulus (rangsangan dari luar), baik yang dapat diamati langsung maupun tidak langsung oleh pihak luar.

Meskipun perilaku adalah bentuk respons atau reaksi terhadap stimulus (rangsangan dari luar), namun dalam memberikan respons, seseorang sangat tergantung pada karakteristik atau faktor-faktor lain dari orang yang bersangkutan. Hal ini berarti meskipun stimulusnya sama bagi beberapa orang, namun respons tiap orang bisa berbeda-beda. Faktor-faktor yang membedakan respons terhadap stimulus disebut determinan perilaku. Determinan perilaku ini dapat dibedakan menjadi dua, yakni: (1) Determinan atau faktor internal, yakni karakteristik orang yang bersangkutan, yang bersifat given atau bawaan, misalnya: tingkat kecerdasan, tingkat emosional, jenis kelamin, dan sebagainya. (2) Determinan atau faktor eksternal, yakni lingkungan, baik lingkungan fisik, sosial, budaya, ekonomi, politik, dan sebagainya. Faktor lingkungan ini sering merupakan faktor dominan yang mewarnai perilaku seseorang.

Pediculosis Capitis adalah infestasi Pediculushumanus var. capitis (atau biasa disebut kutu kepala) pada rambut dan kulit kepala manusia (Djuanda, 2013). Penyakit ini telah menjadi endemik di seluruh dunia baik di negara maju maupun di negara berkembang dan baik di negara beriklim tropis maupun beriklim sedang. Di Amerika Serikat, 6-12 juta orang terinfestasi setiap tahunnya dengan perkiraan 100 juta dollar per tahun dihabiskan untuk pengobatan (Nutanson dkk, 2008). Sebagian besar infestasi kutu terjadi pada anak-anak usia sekolah. Penelitian yang dilakukan oleh Rassami dan Soonwera pada tahun 2012 di Bangkok, Thailand menyatakan bahwa rasio infestasi Pediculus humanus var. capitis pada anak sekolah kelompok usia 12 tahun rasionya $26,07 \%$, sedangkan untuk kelompok usia 8 tahun rasionya meningkat menjadi 55,89\%.

Di Indonesia sendiri, menurut penelitian yang dilakukan oleh Aminah pada tahun 2015 menyatakan bahwa angka kejadian infestasi Pediculus humanus var. capitis pada murid SD Tarakanita Tritis Yogyakarta adalah sebesar 11,3\% dengan total 62 subjek penelitian. Penyakit ini telah lama dihubungkan masyarakat dengan kemiskinan, ekonomi rendah, dan lingkungan yang kumuh. Penyakit ini sering diabaikan karena dianggap ringan, terutama di negara di mana terdapat prioritas kesehatan lain yang lebih serius. Walaupun demikian, penyakit ini telah menyebabkan morbiditas yang signifikan di antara anak-anak sekolah di seluruh dunia. 
Pediculus humanus var. capitis atau yang biasa disebut dengan kutu kepala merupakan ektoparasit obligat yang memakan darah pada manusia. Dalam setiap fase daur hidupnya selalu terkait dengan manusia, tidak terjadi pada hewan, tidak memiliki sayap dan tidak dapat melompat. Penyebaran parasit ini dapat melalui transmisi langsung yaitu kontak kepala dengan kepala dan transmisi tidak langsung melalui pemakaian barang seperti sisir, topi, handuk, bantal, kasur dan kerudung secara bersama.

Beberapa faktor yang dapat membantu penyebaran Pediculosis Capitis adalah faktor sosial-ekonomi, tingkat pengetahuan, personal hygiene yang buruk, kepadatan tempat tinggal, dan karakteristik individu (jenis kelamin, umur, dan panjang rambut) (Hardiyanti dkk, 2015).

Perilaku yang dalam hal ini merupakan perilaku kesehatan adalah respons seseorang terhadap stimulus atau objek yang berkaitan dengan sakit dan penyakit, sistem pelayanan kesehatan, makanan dan minuman, serta lingkungan (Wawan A, 2011).

Pondok pesantren merupakan lembaga pendidikan dengan sistem boarding school (pendidikan dengan asrama) sehingga membentuk komunitas tersendiri yang anggotanya terdiri dari para santri, para guru atau ustadz dan keluarga pengasuh pesantren. Sebagian pesantren di Indonesia masih belum mendapat perhatian yang baik, baik dari pihak pemilik, para anggota warga pesantren itu sendiri, maupun pemerintah, baik dari segi kebersihan, perilaku, maupun kepedulian terhadap kesehatan (Hardiyanti dkk, 2015). Penelitian tentang Pediculosis Capitis pernah dilakukan oleh Rahman di tahun 2014 pada santri Pesantren Rhodlotul Quran Semarang. Hasil yang diperoleh menyatakan bahwa penggunaan tempat tidur/bantal bersama, penggunaan sisir/aksesoris rambut bersama dan panjang rambut memiliki hubungan yang bermakna dengan kejadian Pediculosis Capitis. Pengukuran pengetahuan dapat dilakukan dengan wawancara atau angket yang menanyakan tentang isi materi yang ingin diukur dari subjek penelitian atau responden. Kedalaman pengetahuan yang ingin kita ketahui atau kita ukur dapat kita sesuaikan dengan tingkatan-tingkatan di atas.

Pediculosis Capitis adalah infestasi kulit dan rambut kepala yang disebabkan oleh Pediculus humanus var. capitis yang termasuk famili Pediculidae. Parasit ini hidup di kulit kepala, predileksinya terutama pada bagian belakang kepala (oksipital) dan belakang telinga (retroaurikular). Telur-telurnya (nits) dilekatkan pada dasar tangkai rambut kepala. Biasanya parasit ini menyerang anak-anak dan wanita berambut panjang. 
Parasit ini merupakan parasit obligat, artinya harus menghisap darah manusia agar dapat mempertahankan hidupnya (Djuanda dkk, 2013; Irianto, 2009). Tujuan penelitian ini adalah untuk memperoleh informasi apakah ada hubungan antara perilaku dengan kejadian Peduculosis capitis pada siswi Madrasah Tsanawiyah Hifzil Qur'an Medan.

\section{METODE}

Jenis penelitian yang digunakan adalah penelitian Analitik dengan desain cross sectional untuk melihat hubungan variabel independen dengan variabel dependen. Penelitian dilaksanakan pada bulan Juni s/d Agustus 2017 di Madrasah Tsanawiyah Hifzil Qur'an Medan. Populasi dalam penelitian ini adalah seluruh siswi di Madrasah Tsanawiyah Hifzil Qur'an Medan yang terdiri dari kelas I sebanyak 123 siswi, kelas II sebanyak 93 siswi, dan kelas III sebanyak 57 siswi. Maka jumlah populasi keseluruhan adalah 273 siswi. Jenis data yang digunakan adalah data primer berupa hasil pengisian kuesioner oleh responden dan hasil pemeriksaan rambut responden secara langsung. Data primer diperoleh melalui pengisian kuesioner oleh responden dan pemeriksaan rambut responden secara langsung. Metode pemeriksaan yang digunakan adalah pemeriksaan secara langsung dengan cara penyisiran rambut responden menggunakan sisir rapat (serit) dan pengisian kuesioner.Analisis data dalam penelitian ini menggunakan uji chi square/chi-kuadrat. Metode ini digunakan untuk mengetahui hubungan semua variabel bebas terhadap variabel terikat yang dapat dilakukan sekaligus dengan menggunakan derajat kemaknaan dengan alpha $=0,05$ (derajat kepercayaan 95\%). Bila nilai $\mathrm{p}<0,05$ maka hasil statistik dikatakan bermakna/berhubungan.

\section{HASIL DAN PEMBAHASAN}

1. Gambaran Perilaku dan kasus Pediculosis Capitis Siswi Madrasah Tsanawiyah Hifzil Qur'an Medan

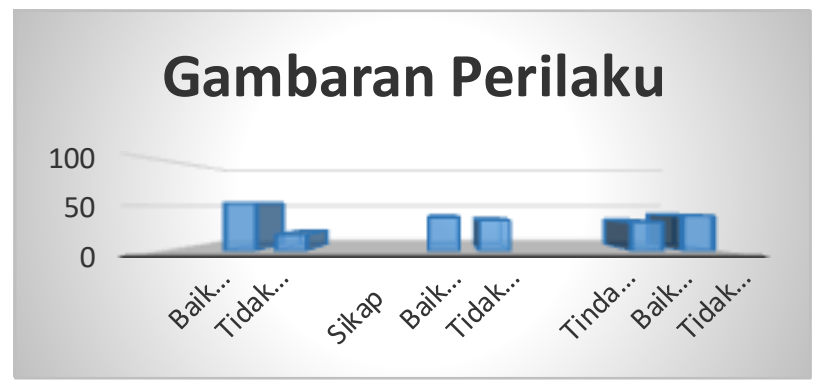

Gambar 1. Gambaran Perilaku siswi tentang Pediculosis capitis di Madrasah Tsanawiyah Hifzil Qur'an Medan tahun 2017. 


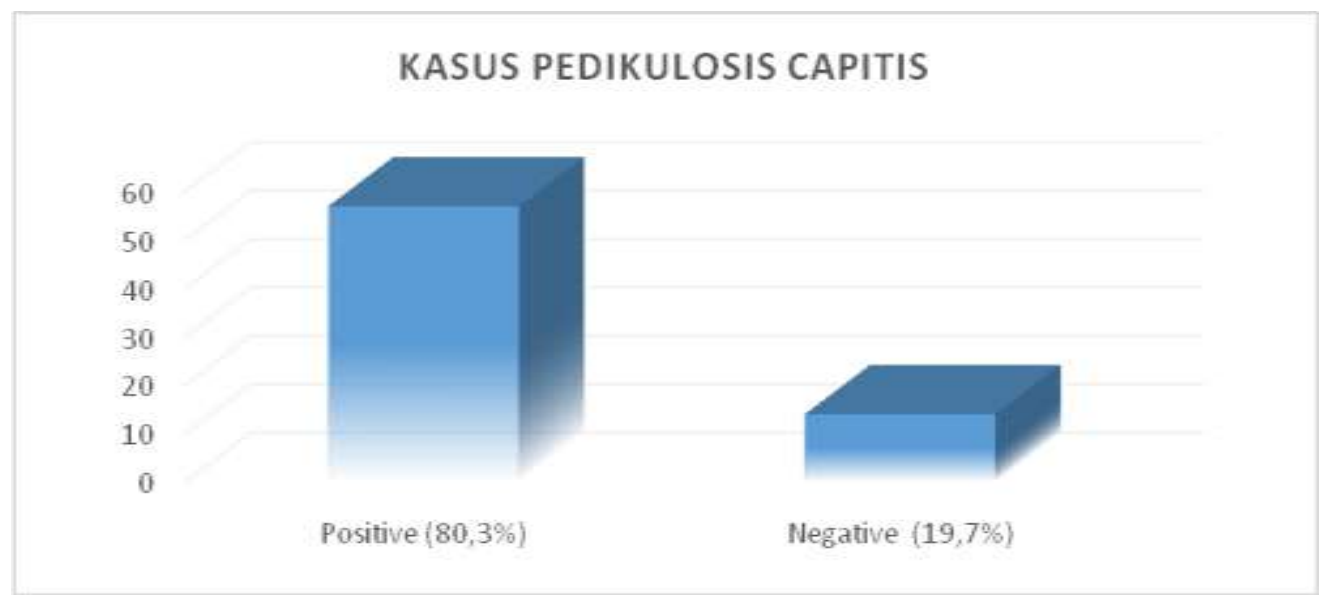

Gambar 2. Gambaran kasus Pediculosis Capitis pada Siswi Madrasah Tsanawiyah Hifzil Qur'an Medan.

Pediculosis Capitis adalah infestasi kulit dan rambut kepala yang disebabkan oleh Pediculus humanus var. capitis yang termasuk famili Pediculidae. Parasit ini hidup di kulit kepala, predileksinya terutama pada bagian belakang kepala (oksipital) dan belakang telinga (retroaurikular). Telur-telurnya (nits) dilekatkan pada dasar tangkai rambut kepala. Biasanya parasit ini menyerang anak-anak dan wanita berambut panjang. Parasit ini merupakan parasit obligat, artinya harus menghisap darah manusia agar dapat mempertahankan hidupnya (Djuanda dkk, 2013; Irianto, 2009).

Infestasi kutu kepala (Pediculus humanus var. capitis) paling sering terjadi pada anak usia pra-sekolah dan sekolah dasar. Penyebarannya dapat melalui transmisi langsung yaitu kontak kepala penderita dan transmisi tidak langsung seperti memakai sisir, topi, handuk, bantal, kasur dan kerudung (Hardiyanti dkk, 2015).

Hasil penelitian di lapangan menunjukkan bahwa dari 71 orang siswi yang diperiksa, sebanyak 57 orang $(80,3 \%)$ positif menderita Pediculosis Capitis. Angka yang sangat tinggi jika dibandingkan dengan hasil penelitian yang dilakukan oleh Aminah (2015) pada murid SD Tarakanita Tritis Yogyakarta yang hanya sebesar 11,3\%. Begitu juga jika dibandingkan dengan hasil penelitian yang dilakukan oleh Rahman (2014) pada santri Pesantren Rhodlotul Quran Semarang, yaitu sebesar 59,3\%. Perbedaan prevalensi atau angka kejadian Pediculosis Capitis di beberapa wilayah ini kemungkinan disebabkan oleh adanya perbedaan faktor yang dapat membantu penyebaran Pediculosis Capitis di beberapa lokasi penelitian, seperti faktor sosial-ekonomi, personal hygiene yang buruk, kepadatan tempat tinggal, dan 
karakteristik individu (jenis kelamin, umur, dan panjang rambut) (Hardiyanti dkk, 2015).

Tingkat pengetahuan dan sikap terhadap Pediculosis Capitis secara umum dalam kategori baik $(74,6 \%$ dan $52,1 \%)$, sementara tindakan secara umum dalam kategori tidak baik $(54,9 \%)$. Dari hasil penelitian ini dapat dilihat bahwa sebagian besar siswi cukup mengetahui dan bersikap baik terhadap hal-hal yang berhubungan dengan Pediculosis Capitis, namun mereka belum mengaplikasikan pengetahuan dan sikap tersebut dalam bentuk tindakan nyata di kehidupan seharihari. Responden dengan sikap kategori baik berjumlah 37 orang $(52,1 \%)$. Sikap masih merupakan kesiapan atau kesediaan untuk bertindak, bukan pelaksanaan motif tertentu. Tindakan responden berdasarkan hasil penelitian umumnya dalam kategori tidak baik $(54,9 \%)$.

2. Hubungan Perilaku dengan Kejadian Pediculosis Capitis pada Siswi Madrasah Tsanawiyah Hifzil Qur'an Medan

Tabel 1. Hubungan Pengetahuan Siswa dengan Kejadian Pediculosis Capitis di Madrasah Tsanawiyah Hifzil Qur'an Medan

\begin{tabular}{|c|c|c|c|c|c|c|c|}
\hline \multirow{3}{*}{ Pengetahuan } & \multicolumn{4}{|c|}{ Pediculosis Capitis } & \multirow{2}{*}{\multicolumn{2}{|c|}{ Jumlah }} & \multirow{3}{*}{$p$-value } \\
\hline & \multicolumn{2}{|c|}{ Positif } & \multicolumn{2}{|c|}{ Negatif } & & & \\
\hline & $\mathbf{N}$ & $\%$ & $\mathbf{N}$ & $\%$ & $\mathbf{N}$ & $\%$ & \\
\hline Baik & 43 & 60,6 & 10 & 14,1 & 53 & 74,6 & \\
\hline Tidak baik & 14 & 19,7 & 4 & 5,6 & 18 & 25,4 & 0,757 \\
\hline Jumlah & 57 & 80,3 & 14 & 19,7 & 71 & 100 & \\
\hline
\end{tabular}

Tabel 2. Hubungan Sikap Siswa dengan Kejadian Pediculosis Capitis di Madrasah Tsanawiyah Hifzil Qur'an Medan

\begin{tabular}{cccccccc}
\hline \multirow{2}{*}{ Sikap } & \multicolumn{4}{c}{ Pediculosis Capitis } & \multicolumn{2}{c}{ Jumlah } & \multirow{2}{*}{ p-value } \\
\cline { 2 - 6 } & \multicolumn{2}{c}{ Positif } & \multicolumn{2}{c}{ Negatif } & & \\
\cline { 2 - 6 } & $\mathrm{N}$ & $\%$ & $\mathrm{~N}$ & $\%$ & $\mathrm{~N}$ & $\%$ & \\
\hline Baik & 28 & 39,4 & 9 & 12,7 & 37 & 52,1 & \multirow{2}{*}{0,309} \\
\hline Tidak baik & 29 & 40,8 & 5 & 7,0 & 34 & 47,9 & \\
\hline Jumlah & 57 & 80,3 & 14 & 19,7 & 71 & 100 & \\
\hline
\end{tabular}

Tabel 3. Hubungan Tindakan Siswa dengan Kejadian Pediculosis Capitis di Madrasah Tsanawiyah Hifzil Qur'an Medan

\begin{tabular}{cccccccc}
\hline \multirow{2}{*}{ Tindakan } & \multicolumn{4}{c}{ Pediculosis Capitis } & \multicolumn{2}{c}{ Jumlah } & \multirow{2}{*}{$\boldsymbol{p}$-value } \\
\cline { 2 - 7 } & \multicolumn{2}{c}{ Positif } & \multicolumn{2}{c}{ Negatif } & & \\
& $\mathrm{N}$ & $\%$ & $\mathrm{~N}$ & $\%$ & $\mathrm{~N}$ & $\%$ & \\
\hline Baik & 21 & 29,6 & 11 & 15,5 & 32 & 45,1 & \multirow{2}{*}{0,005} \\
\hline Tidak baik & 36 & 50,7 & 3 & 4,2 & 39 & 54,9 \\
\hline Jumlah & 57 & 80,3 & 14 & 19,7 & 71 & 100 & \\
\hline
\end{tabular}


Responden dengan tingkat pengetahuan yang baik berjumlah 53 orang $(74,6 \%)$. Hasil uji chi-square terhadap pengetahuan dengan kejadian Pediculosis Capitis menunjukkan bahwa tidak ada hubungan yang bermakna antara tingkat pengetahuan dengan kejadian Pediculosis Capitis dengan nilai $p$-value $=0,757(>0,05)$. Hal ini menunjukkan bahwa umumnya responden sudah mempunyai pengetahuan yang baik mengenai Pediculosis Capitis, baik didapat dari sekolah misalnya melalui kegiatan Unit Kesehatan Sekolah (UKS), maupun di rumah. Namun angka kejadian pediculosis Capitis masih tinggi. Hal ini karena pengetahuan masih hanya sebatas pikiran, belum merupakan suatu tindakan nyata, sehingga tidak menjamin seseorang akan mempunyai sikap dan tindakan yang baik pula terhadap suatu hal. Menurut Notoatmodjo (2012), pengetahuan sendiri merupakan hal yang sangat penting dalam membentuk tindakan seseorang. Seseorang yang mempunyai pengetahuan yang baik akan suatu hal diharapkan akan mempunyai sikap yang baik terhadap hal tersebut. Sikap yang baik terhadap suatu hal diharapkan akan mempunyai tindakan yang baik pula. Hasil uji chi-square terhadap sikap dengan kejadian Pediculosis Capitis memperoleh nilai $p$ value $=0,309(>0,05)$, artinya tidak terdapat hubungan yang bermakna antara sikap dengan kejadian Pediculosis Capitis. Dari hasil ini dapat dilihat bahwa responden umumnya menunjukkan sikap yang baik terhadap hal-hal yang berhubungan dengan Pediculosis Capitis, namun angka kejadian Pediculosis Capitis tetap saja tinggi. Ini karena sikap sendiri menurut pendapat Notoatmodjo (2012) belum merupakan suatu tindakan atau suatu aktivitas, akan tetapi masih merupakan predisposisi terhadap suatu tindakan.

Hasil uji chi-square terhadap tindakan dengan kejadian Pediculosis Capitis memperoleh nilai $p$-value $=0,005(<0,05)$, artinya terdapat hubungan yang bermakna antara tindakan dengan kejadian Pediculosis Capitis. Hal ini menunjukkan bahwa meskipun responden memiliki tingkat pengetahuan dan sikap yang baik, tetapi angka kejadian Pediculosis Capitis tetap saja tinggi. Ini karena tindakan adalah hal yang paling mempengaruhi kejadian Pediculosis Capitis. Seseorang yang memiliki tingkat pengetahuan dan sikap yang baik, jika tidak mengaplikasikan hal tersebut ke dalam bentuk tindakan nyata maka hasilnya akan sama saja. 
Dari penjelasan di atas dapat dilihat bahwa tidak adanya hubungan yang bermakna antara pengetahuan dengan kejadian Pediculosis Capitis karena para siswi umumnya memiliki pengetahuan yang baik tentang hal-hal yang berhubungan dengan Pediculosis Capitis, namun prevalensi Pediculosis Capitis masih saja tinggi di sekolah tersebut. Begitu juga dengan sikap, tidak adanya hubungan yang bermakna antara sikap dengan kejadian Pediculosis Capitis karena para siswi umumnya telah memiliki sikap yang baik tentang hal-hal yang berhubungan dengan Pediculosis Capitis, namun prevalensi Pediculosis Captis masih saja tinggi di sekolah tersebut. Sementara untuk tindakan dapat dilihat bahwa adanya hubungan yang bermakna antara tindakan dengan kejadian Pediculosis Capitis karena umumnya siswi walaupun memiliki pengetahuan dan sikap yang baik terhadap hal-hal yang berhubungan dengan Pediculosis Capitis, namun mereka tidak mengaplikasikan pengetahuan dan sikap mereka tersebut menjadi tindakan nyata, sehingga prevalensi Pediculosis Capitis tetap saja tinggi di sekolah tersebut.

Menurut Notoatmodjo (2012), banyak faktor yang mempengaruhi terwujudnya pengetahuan dan sikap menjadi tindakan nyata, salah satu faktor yang dominan adalah lingkungan. Dari hasil pengamatan, asrama khusunya ruang kamar siswi Madrasah Tsanawiyah Hifzil Qur'an Medan memiliki kondisi lingkungan yang bersih, hanya saja masih cukup padat, sehingga sangat memungkinkan untuk terjadinya penularan Pediculosis Capitis ketika sedang bermain atau belajar bersama di dalam kamar.

\section{SIMPULAN}

Berdasarkan hasil penelitian ini dapat disimpulkan beberapa hal sebagai berikut: Angka kejadian Pediculosis Capitis pada siswi Madrasah Tsanawiyah Hifzil Qur'an Medan cukup tinggi yaitu sebesar 80,3\%. Tidak ada hubungan yang bermakna antara pengetahuan dan sikap dengan kejadian Pediculosis Capitis pada siswi Madrasah Tsanawiyah Hifzil Qur'an Medan. Ada hubungan yang bermakna antara tindakan dengan kejadian Pediculosis Capitis pada siswi Madrasah Tsanawiyah Hifzil Qur'an Medan.

\section{DAFTAR RUJUKAN}

Aminah, N., 2015. Angka Kejadian Infestasi Kutu Kepala (Pediculus Humanus Capitis) pada Anak SD Tarakanita Tritis Pakem Sleman Yogyakarta. [Skripsi]. Yogyakarta: Fakultas Kedokteran Universitas Gajah Mada.

Ansyah, A.N., 2013. Hubungan Antara Personal Hygiene dengan Angka Kejadian Pediculosis Capitis pada 
Santri Putri Pondok Pesantren Modern Islam Assalaam Surakarta. [Skripsi]. Surakarta: Fakultas Kedokteran Universitas Muhammadiyah Surakarta.

Centers for Disease Control and Prevention, 2013. Parasite Lice Head Lice, [online] Tersedia di: <https://www.cdc.gov/parasites/lice/ head/index.html> [Diakses pada 17 Maret 2017]

Djuanda, A., Hamzah, M., dan Aisah, S., 2013. Ilmu Penyakit Kulit dan Kelamin. Jakarta: Fakultas Kedokteran Universitas Indonesia.

Hardiyanti, N.I., dkk., 2015. Penatalaksanaan Pediculosis Capitis. Majority. 4(9): 47-52.

Irianto, K., 2009. Parasitologi Berbagai Penyakit yang Mempengaruhi Kesehatan Manusia. Bandung: Yrama Widya.

Notoatmodjo, S., 2012. Promosi Kesehatan dan Perilaku Kesehatan. Jakarta: Rineka Cipta.
Nutanson, I., dkk., 2008. Pediculus Humanus Capitis: An Update. Acta Dermatoven APA. 17(4): 147-153.

Rahman, Z.A., 2014. Faktor-Faktor yang Berhubungan dengan Kejadian Pediculosis Capitis pada Santri Pesantren Rhodlotul Quran Semarang. [Skripsi]. Semarang: Fakultas Kedokteran Universitas Diponegoro.

Rassami, W., dan Soonwera, M., 2012. Epidemiology of Pediculosis Capitis Among Schoolchildren in the Eastern Area of Bangkok, Thailand. Asian Pac J Trop Biomed. 2(11): 901-904.

Sembel, D.T., 2009. Entomologi Kedokteran. Yogyakarta: Penerbit Andi.

Wawan, A., dan M., Dewi, 2011. Teori dan Pengukuran Pengetahuan, Sikap, dan Perilaku Manusia. Yogyakarta: Nuha Medika. 